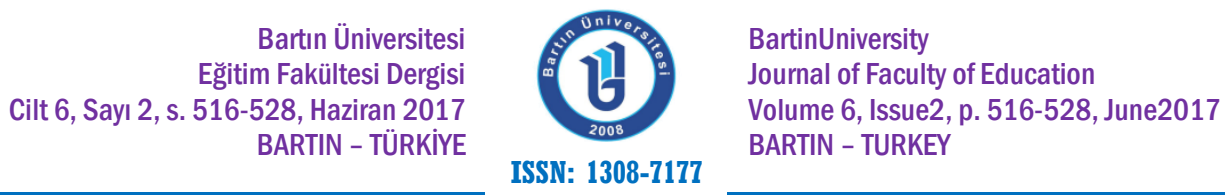

Doi: 10.14686/buefad.298576

\title{
İyonlaşma Enerjisi Tanımına Kavramsal Yaklaşım
}

Ayşe YALÇIN ÇELIKK, Dr, Gazi Üniversitesi Gazi Eğitim Fakültesi, ayseyalcin@gazi.edu.tr

Ziya KILIÇ, Prof. Dr., Gazi Üniversitesi Gazi Eğitim Fakültesi, zkilic@gazi.edu.tr

Öz: Kimya, soyut kavramları çok olan ve kavramsal ağırlıklı bir bilimdir. Bu kavramların tanımı, kavramların içeriğine uygun olarak yapılmalı ve tanımlarda kimya öğretimi de dikkate alınmalıdır. Kavramların sadece bilimsel olarak doğru olması yeterli değildir. Bu araştırmada, "iyonlaşma enerjisi" kavramı kimya öğretiminin amaçları açısından kavramsal olarak incelendi ve 35 ders kitabında yer alan tanımlar bilimsel görüşü yansıtması ve anlaşılırlığı açısından değerlendirildi. İyonlaşma enerjisini tanımlarken elektronu koparılacak olan atomun ve bu atomdan koparılacak olan elektronun konumunun belirtilmesi önemlidir. Ancak basım dili İngilizce ve Türkçe olan ders kitaplarında iyonlaşma enerjisi tanımlanırken atomun konumu için "gaz halindeki bir atom" veya "gaz halindeki nötral bir atom"; elektronun konumu içinde "en dış kabuktaki elektron" veya "en gevşek bağı elektron" ifadelerinin sıklıkla tercih edildiği belirlendi. Ders kitaplarındaki bu tanımların genellikle IUPAC'ın tanımı ile uyumsuz olduğu ve iyonlaşma enerjisinin öğrenilebilmesi için uygun olmadığı sonucuna varıldı.

Anahtar Kelimeler: iyonlaşma enerjisi, alternatif kavramalar, kimya eğitimi, temel kavramlar, ders kitabı inceleme

\section{A Conceptual Approach to the Definition of Ionization Energy}

\begin{abstract}
Chemistry is a concept-based discipline with numerous abstract concepts. These concepts should be defined appropriately for their content and chemistry education should also be taken into consideration in definitions. Scientific correctness of the concepts is not sufficient. This study analyzes the concept of ionization energy in terms of the targets of chemistry education and evaluates the definitions in textbooks in terms of reflecting scientific opinion and comprehensibility. It is important to indicate the location of the atom from which the electron will be ejected and the electron to be ejected from this atom while defining ionization energy. However, it was observed that the expressions of "a gaseous atom" or "a neutral gaseous atom" were frequently used for the location of the atom and the expressions of "the valence shell electron" or "the loosest-bound electron" were frequently used for the location of electron in the textbooks printed in English or Turkish. These definitions in textbooks do not comply with the definition of the IUPAC and not suitable for educational purposes.
\end{abstract}

Key Words: ionization energy, alternative conceptions, chemistry education, basic concepts, textbook review 


\section{GiRiş}

Ortaöğretimden üniversiteye farklı seviyedeki birçok öğrenci kimyayı öğrenmek için gayret göstermelerine rağmen genellikle başarısız olmaktadırlar. Bu başarısızlığın en önemli nedenlerinden biri, kimyanın temel kavramlarını bilimsel doğrulara uygun şekilde yapılandıramamalarıdır (Nakhleh, 1992). Kimya, kavram ağırlıklı bir bilimdir. Kimya öğretim programı, kimya ve diğer bilim dallarının öğrenilmesini etkileyen çok sayıda soyut kavram içermektedir (Ben-Zvi, Eylon ve Silberstein, 1986). Bu kavramların öğrenciler tarafından bilimsel görüşe uygun olarak öğrenilmesi, kimya öğretiminin temel amaçlarındandır (Barke, Hazari ve Yitbarek, 2009; Nakhleh, 1992; Taber, 2002). Ancak, soyut kavramların öğretmenler tarafından öğretimi ve öğrenciler tarafından öğrenilmesi oldukça zordur (Barker, 2000). Özellikle 2000'li yıllara doğru öğrencilerin kimyanın temel kavramlarını nasıl kavradıkları ve bilimsel görüşe uygun olmayan kavramaları hakkında pek çok çalışma yapılmıştır. Öğrencilerin bilimsel doğrulardan sapan kavramları fen eğitimi literatüründe "yanlış kavrama" veya "alternatif kavrama" gibi terimlerle ifade edilmiştir (Griffiths, Thomey, Cooke ve Normore, 1988; Nakhleh, 1992; Nussbaum, 1981; Schmidt, 1997; Treagust, 1988). Çok fazla olmasa da günümüzde öğrenci alternatif kavramaları ve bunların nedenleriyle ilgili kimya eğitimi literatüründe yayınlara rastlanmaktadır (Bretz ve McClary, 2015). Temel kimya kavramları öğrenilemeyince, bunlarla tanımlanan diğer kavramları da yapılandırmak öğrenciler için zor olmaktadır. Bir kavramı veya kuramı bilimsel doğrulara uygun olarak kavrayamayan öğrenciler, kendi kavram ve kuramlarını geliştirmekte ve bunlar bilimsel açıdan doğru olmadığından, kimya konularını ezberlemek zorunda kalmaktadırlar.

Bazı konular kimya öğretmenleri tarafından basit olarak yorumlanmasına rağmen, içerdiği soyut kavramlar nedeniyle öğrenciler için öğrenilmesi zor olabilir. Örneğin, kimya öğretim programındaki bağlar konusu öğrencilerin öğrenmede zorluk yaşadığı konulardan biridir (Coll ve Treagust, 2003). Genel olarak "bağ" kavramı ile maddenin taneciklerini oluşturan atom-iyon-moleküller arası çekim kuvvetleri ve "kimyasal bağ" kavramı ile de elektronların ortaklaşa kullanımı ve iyonlar arası çekim kuvvetleri ifade edilmektedir. Kimyadaki birçok konu "bağ ve kimyasal bağ" ile ilişkilendirilerek öğretilmektedir (Barke, Hazari ve Yitbarek, 2009; Coll ve Treagust, 2003). Aşağıda bu konulara birkaç örnek verildi:

$\checkmark$ Erime ve kaynama (bir sıvının tanecikleri arasındaki etkileşim kuvveti fazlaysa, erime ISıSı ve kaynama sıcaklığı yüksektir)

$\checkmark$ Çözeltilerde kaynama noktası yükselmesi (sudaki hidrojen bağlarının yerini $\mathrm{NaCl}$ çözeltisinde dipol-iyon bağ kuvvetleri aldığından, çözeltinin kaynama noktası suya göre daha yüksektir)

$\checkmark$ Asitlik kuvveti (bileşikte iyonlaşabilir özellikteki hidrojenin yaptığı kimyasal bağ ne kadar kuvvetliyse, bileşik o kadar zayıf asittir)

$\checkmark$ Kimyasal tepkimeler (kimyasal tepkimeler, enerjinin azaldığı -daha kuvvetli bağların oluştuğu- yöne doğru kendiliğinden gerçekleşme eğilimindedir)

"Bağ" kavramını anlayamayan bir öğrencinin bu konuları ve bu konularla bağlantılı olan konuları öğrenebilmesi zor olacaktır. Bu sebeple temel kimya kavramlarının ders kitapları veya öğretmenlerce bilimsel görüşe uygun olacak şekilde tam ve net olarak öğrenilmesi ve ifade edilebilmesi gerekir.

Kimya bilgilerinin sarmal özelliğinden dolayı, kimya öğretim programlarında yıllara göre maddenin önce bütünsel ve sonra tanecikli yapısı, daha sonra bu taneciklerin özellikleri ve etkileşimleri ile ilgili bilgilere yer verilmektedir. Örneğin, maddenin bütünsel yapısının öğrenildiği yıllarda element; "...kendisinden daha basit maddelere ayrılamayan saf madde..." şeklindeki tanımlanırken, tanecikli yapı ve tanecikler öğrenildiğinde "...aynı cins atomların 
bulunduğu madde.." şeklinde tanımlanmaktadır (Talim Terbiye Kurulu [TTK], 2005). Asitlikbazlıkla ilgili Arrhenius tanımlarından sonra Lowry-Bronsted ve Lewis tanımları öğrenilmektedir. Kimya bilgisinin bu sarmal yapısı bir yerinden koparsa, diğer konuların öğrenciler için ezberlenmesi zorunlu hale gelir.

"Maddenin tanecikli ve boşluklu yapısı" fen eğitiminde çok önemli anahtar bir kavramdır (NRC, 1996; Tsaparlis ve Sevian, 2013). Maddenin tanecikleri "atom, iyon, molekül"dür. "Tanecik" kavramı kimi zaman birçok öğrenci için öğrenmenin önünde bir engel oluşturur. Çünkü temsili olarak çizilen bir küre su olurken başka bir küre şeker olabilmekte; bu iki kürenin karışım olarak çizilmesi ise çözünme olarak adlandırılmaktadır. Hatta çizilen bir küre kimi zaman atom, kimi zaman iyon ya da molekülü sembolize etmektedir (Barke, Hazari ve Yitbarek, 2009). Kimya eğitimcilerine göre maddenin taneciklerini ve tanecikli yapı kuramını kavrayamayan öğrencilerin; tanecikli yapı kuramına dayanan katılar, sıvılar, gazlar, karışımlar, element, bileşik gibi kimyanın temel kavramlarını öğrenemezler ve bu nedenle kimyayı öğrenmeleri de zorlaşır (Gabel ve Samuel, 1987).

Atomlar, iyonlar ve moleküller de etkileşerek birbirlerine dönüşebilirler ve bu dönüşüm süreçleri kimyanın en önemli konuları arasındadır. Atom ve moleküllerden iyonların oluşumu "iyonlaşma" olayıdır ve bu çalışmada "iyonlaşma" kavramsal olarak incelenecektir.

\section{1. İyonlaşma Enerjisi}

İyonlaşma enerjisi kavramı atomik yapı, periyodik çizelgedeki değişimler ve kimyasal tepkimeler ile ilgili konuların kavranmasında temel rol oynar (Taber, 2003) ancak bu konu öğrencilerin anlamakta zorluk çektiği bir konudur (Taber, 1998; Taber, 2003). Tanecikli yapı ve tanecik özellikleriyle ilgili "iyonlaşma enerjisi" konusunda "öğrencilerin açıklamaları" nın tartışıldığı çalışmalarda; öğrencilerin temel ilkeleri kavrayamamaları nedeniyle iki önemli alternatif kavram geliştirdikleri belirtilmiştir: Bunlardan ilki, bir atomun bir kabuğunun dolu olması atom tarafından istenen ve kararlı olan bir durumdur. Bu kavramaya göre $\mathrm{Na}^{7-}$, veya $\mathrm{C}^{4+}$ $\mathrm{Cl}^{7+}$ iyonları kararlıdır. Ya da dolu bir kabuğa sahip olan bir atom/iyondan başka bir elektron koparılamaz. Bu alternatif kavrama daha sonraki çalışmalarda "oktete uyan yapı" olarak tanımlanmıştır (Tan vd. 2005; Tan vd. 2008; Tan ve Taber, 2009). Diğer alternatif kavrama ise atom iyonlaştıktan sonra, ikinci elektronu uzaklaştırmak için gerekli enerji daha fazladır, çünkü bu elektron çekirdeğe daha yakındır (kuvvetin korunumu) (Taber, 1998; Taber, 2002; Taber, 2003). Bu kavramaya göre öğrenciler çekirdek etkin yükünü dikkate almamaktadır. Bu çalışmalara ilaveten farklı öğrenci grupları ile çalışmalar da gerçekleştirilmiştir. Bu çalışmaların sonuçları da birbirine benzemektedir (Tan vd. 2008; Tan ve Taber, 2009; Taber ve Tan, 2011).

İyonlaşma enerjisiyle ilgili Türkiye' de yapılan çalışmalar çok azdır (Genç, 2008; Tezcan ve Kıpık, 2005) ve sadece Genç (2008) iyonlaşma enerjisi ile ilgili alternatif kavramaları tespit etmiştir. Genç, lise öğrencilerinin "atom kararlı hale geçebilmek sürekli elektron verebilir" veya "magnezyum atomuna göre sodyum atomunda daha az elektron olduğu için elektron başına düşen çekim kuvveti daha fazladır" gibi alternatif kavramaları olduğunu belirlemiştir. Bu alternatif kavramalar da Taber'in $(1998 ; 2002)$ tespit ettiği alternatif kavramalarla uyumludur.

\subsection{Alternatif Kavramaların Kaynağı: Ders Kitapları}

Ders kitapları öğretim sırasında öğretmenler ve öğrenciler için iyi bir kaynaktır. Öğretmenler ders kitaplarını, dersin içeriğini ve kendi öğretimlerine yön vermek için kullanırlar. Diğer taraftan ders kitapları, içeriğin sunumu ve organize etmesi açısından da öğrenme işini öğrenci için eğlenceli hale getirir. Öğrenciler ders kitaplarını bilgi edinmede etkili bir kaynak olarak görmektedir (Köseoğlu vd. 2003). Ders kitapları öğrenme sürecine doğrudan etki edebilir. Bu nedenle ders kitaplarında içerik, anlam, dil bilgisi ve baskı açısından hatalar 
içermemelidir. Ders kitaplarında temel kavramların tanımlarının doğru yapılmış olması yeterli değildir, mutlaka onu okuyan öğrencilerin de bu kavramları doğru olarak kavramaları sağlanacak şekilde olmalıdır (Kılıç vd. 2001).

Öğrencilerin alternatif kavramalara sahip olmasında onların geçmiş yaşantıları önemli bir etkendir (Harrison ve Treagust, 1996); bununla birlikte ders kitapları da öğrencilerin kavramları bilimsel görüşe uygun şekilde kavramalarına engel olabilir (Harrison ve Treagust, 1996; Sanger ve Greenbowe, 1999; Staver ve Lumpe, 1993; Yalçın ve Kılıç, 2005). Eğitim literatürü incelendiğinde hemen hemen her alanla ilgili öğrencilerin alternatif kavramalarını ve ders kitaplarının bunlara etkisini araştıran çalışmalar görülmektedir. Örneğin; Nakiboğlu (2003), kimya öğretmen adaylarının atomik orbital konusuyla ilgili alternatif kavramalarını belirlediği çalışmasında atomun yapısını güneş sistemi modeli ile açıkladıkları ve orbitali "elektronun bulunduğu bir kutu" gibi algıladıklarını tespit etmiştir. Nakiboğlu, üniversite öğrencilerinin bu tür açıklamalarının kaynağını lise ders kitaplarında atomun yapısını açıklamada, sıklıkla, ilk tercih edilen modelin güneş sistemi modeli olmasına ve ders kitaplarında orbital ile ilgili gösterimlere bağlamıştır.

Ders kitaplarının öğrencilerde yanlış kavramalara neden olduğu Sanger ve Greenbowe'nın (1997) araştırma sonuçlarıyla da ortaya konulmuştur. Sanger ve Greenbowe, üniversite öğrencilerinin elektrolitik çözeltilerdeki ve tuz köprüsündeki elektrik akımını nasıl modellediklerini belirlemek amacıyla yaptıkları mülakatlarda çeşitli alternatif kavramaları belirlemiş ve bunların kaynaklarının ders kitabı olduğunu ileri sürmüştür. Bu çalışmanın sonunda, öğrencilerin "elektronun çözelti içerisinde hareket ettiği veya bir iyondan diğerine atlayabildiği" kavramalarının, kullanmakta oldukları ders kitapları ile uyumlu olduğunu görmüşler ve bu nedenle de ders kitaplarını alternatif kavrama kaynağı açısından da incelemek gerektiğini ifade etmişlerdir.

Yalçın ve Kılıç (2005) da lise öğrencilerinin radyoaktivite konusundaki alternatif kavramalarını ve ders kitaplarının bu konuyu nasıl açıkladıklarını araştırmıştır. Çalışmanın sonunda, öğrencilerin sahip olduğu alternatif kavramalarla ders kitaplarındaki yanlış ifadeler arasında önemli benzerlikler olduğu ve ders kitaplarında konunun sunuluşundaki ifadelerin, kullanılan resim ve şekillerin öğrencilerin alternatif kavramalarını destekleyebilecek tarzda olduğunu ifade etmişlerdir. Benzer şekilde Tekin ve Nakiboğlu (2006) de lise öğrencilerinin bağlanma enerjisi ile ilgili alternatif kavramalarının olduğunu ve bu kavramaların ders kitapları ile örtüştüğünü belirlemiştir

\subsection{Araştırmanın Amacı}

$\mathrm{Bu}$ araştırmanın yazarlarından biri, üniversitede lisansüstü düzeydeki Genel Kimya Kavramları dersinde, dersin içeriği ve amacı konusunda öğrencileri bilgilendirirken genellikle "1. molar iyonlaşma enerjisi" kavramının tanımını yapmalarını istemesine rağmen, hemen hemen hiçbir öğrenciden tatminkâr cevap alamamıştır. Hâlbuki iyonlaşma kavramı kimya öğretiminin ilk yıllarında öğrenilmekte ve pek çok kimya konusunun da temelini oluşturmaktadır. Ayrıca, Taber (2003) iyonlaşma enerjisi konusunda öğrencilerin açıklamalarını değerlendirdiği bir çalışmasında, "iyonlaşma ve iyonlaşma enerjisinin tanımlanması" konusunda yapılacak araştırmaların önemine vurgu yapmıştır. Bu nedenle, iyonlaşma enerjisinin tanımlanması ve ders kitaplarında yer alan tanımların değerlendirilmesi amacıyla bu çalışma gerçekleştirildi. Ders kitaplarındaki bu konu ile ilgili tanımlamada hangi alt kavramlara vurgu yapıldığı ve bu tanımların bilimsel görüşe uygunluğu incelemede esas alındı. 


\section{YÖNTEM}

Bu çalışma, gözlem, görüşme ve doküman analizi gibi veri toplama yöntemlerinin kullanıldığı nitel araştırma deseni esas alınarak gerçekleştirildi (Bogdan ve Biklen, 1992; Yıldırım ve Şimşek, 2008). Basım dili Türkçe ve İngilizce 35 kimya ders kitabının incelendiği bu çalışmada veriler içerik analizi ile elde edildi. İçerik analizi sırasında; ders kitaplarındaki tanımlar birbirleriyle karşılaştııılarak sınıflandırıldı. Bu sınıflamalar tanımı açıklayabilecek etiket ve temalara dönüştürüldü.

\section{1 Örneklem}

$\mathrm{Bu}$ araştırmada yurt içi ve yurt dışında basılan 35 adet lise ve üniversite ders kitabı incelendi. Bu kitapların 21 tanesinin basım dili İngilizce, 14 tanesinin ise Türkçedir. Basım dili Ingilizce olan kaynakların 4 tanesi Türkçe' ye de çevrilmiş üniversite ders kitabıdır. Böylelikle, 17 tane İngilizce, 18 tane Türkçe kitap incelendi. Ingilizce kitaplardan 6'sı lise ve $11^{\prime} i$ de üniversite ders kitabıdır. Yurt dışı kaynaklı tüm kitaplar internet kanalıyla açık veya sınırlı erişimi olan kitaplardır. Basım dili Türkçe olan kaynakların 14'ü lise ve 4'ü de üniversite ders kitabıdır. Lise ders kitaplarının hepsi 2012 yılından itibaren Talim Terbiye Kurulu Başkanlığı'nca onaylanarak liselerde ders kitabı olarak kabul edilmiş kitaplardır.

Araştırmada incelenen kitaplar Ek' de verildi.

\subsection{Veri Toplama Süreci ve Verilerin Analizi}

Bu araştırmada doküman analizi tekniği kullanıldı. Bu teknikte araştırmanın amacıyla ilgili yazıı materyallerin veri kaynağı olarak incelenmesi esastır (Yıldırım ve Şimşek, 2008; Karasar, 2008). Araştırmanın amaçları doğrultusunda belirlenen kimya kitaplarında "iyonlaşma enerjisi" kavramının nasıl tanımlandığı her iki araştırmacı tarafından dikkatli bir şekilde incelendi. Araştırmanın başında İngilizce ve Türkçe kitaplar arasında ayırım yapabilmek için; İngilizce lise kitapları (iL) ve üniversite kitapları (iÜ), Türkçe lise kitapları (TL) ve üniversite kitapları ise (TÜ) olarak sınıflandırıldı.

Basım dili İngilizce olan kitaplardaki tanımlar ilk önce araştırmacılar tarafından Türkçe 'ye çevrildi. Daha sonra öğretim dili İngilizce olan Türkiye'deki bir üniversitede lisans ve lisansüstü düzeyde eğitim veren bir uzmana çevirilerin uygunluğu kontrol ettirildi. Uzmandan onay alındıktan sonra ilgili kavramların Türkçe kaynaklardaki tanımlar ve İngilizce kaynaklardan Türkçeye çevrilmiş tanımlar açık kodlama ile analiz edildi. Her bir ifade içerik açısından kontrol edilerek uygun etiket ve temalar altında toplandı. Bu değerlendirme süreci her iki araştırmacı tarafından da yapıldı. Böylelikle nihai etiket ve temalar oluşturuldu.

\section{BULGULAR}

Bu kısımda; ders kitaplarının iyonlaşma enerjisi ile ilgili tanımlamaları değerlendirilmeden önce bu kavramın nasıl tanımlanması gerektiğine vurgu yapıldı. Daha sonra iyonlaşma enerjisi kavramının ders kitaplarında nasıl tanımlandığı açıklandı.

\section{1. İyonlaşma enerjisine kavramsal yaklaşım}

Bir atomdaki elektronlar çekirdeğin elektrostatik çekim alanı altındadır ve atomdan elektronları koparmak için mutlaka enerji verilmesi gerekir. Atomdan bir ya da daha fazla elektron koparılırsa atom iyonlaşır. Atomlar katı, sıvı veya gaz halindeki maddelerin yapı taşları olabilir ve bu durumda itme-çekme kuvvetlerinin etkisi altında olacaklarından, bunlardan elektron koparmak bulundukları ortama göre daha kolay (daha az enerji gerektirir) veya daha 
zor (daha çok enerji gerektirir) olabilir. Bu nedenle, iyonlaşma enerjisinin tanımında ilk dikkate alınması gereken durum, tanımda yer alan atomun konumudur.

Modern atom kuramına göre, elektronlar çekirdeğin etrafında dönerler ve çekirdekten uzaklaştıkça enerjilerinde artış olur. Bir atomun en dış orbitalindeki elektronlar en yüksek enerjilidirler (Pauling, 1970). Bir atom enerji alırsa, bu elektronlar daha üst enerji seviyelerine çıkarlar. Bu olaya atomun uyarılması denir (Skoog, Holler ve Crouch, 2007). Eğer atom yeterli enerji alırsa, dış kabuktaki elektron(lar) çekirdeğin çekim alanından kurtularak uzaklaşır ve atom iyonlaşır. Bu olay iyonlaşma, bu sırada atomun aldığı enerji ise iyonlaşma enerjisidir. Ancak, atomdan kopartılacak olan elektron farklı enerji seviyelerinde olabileceğinden, kavramsal olarak iyonlaşma enerjisinin tanımında bu elektronun konumu da belirtilmelidir.

Pek çok çalışmada örnek olarak sodyum ( $\mathrm{Na}$ ) atomu verildiğinden, biz de sodyum atomuna göre açıklama yapacağız. Sodyum atomunun elektron dizilişi " $1 s^{2} 2 s^{2} 2 p^{6} 3 s^{1}$ " şeklindedir. Temel haldeki bir sodyum atomu önce $5890 \AA$ ve sonra $6160 \AA^{\prime}$ daki fotonları absorplayarak $3 s^{1} \rightarrow 3 p^{1} \rightarrow 5 s^{1}$ geçişlerini veya $2852 \AA^{\prime}$ daki fotonu absorplayarak $3 s^{1} \rightarrow 5 p^{1}$ geçişini yapabilir (Skoog, Holler ve Crouch, 2007). Na atomunun 3p, $5 s$ veya $5 p$ deki bu elektronu atomdan koparılırsa, sodyum atomu iyonlaşır. Ancak bu olay sırasında verilen enerji "iyonlaşma enerjisi" olarak tanımlanamaz.

İyonlaşma enerjisi kavramının tanımında sodyum atomunun temel halde olduğunun, yani koparılacak olan elektronun 3s orbitalinde bulunduğunun belirtilmesi şarttır.

Sodyumun I. molar iyonlaşma enerjisi 495,8 kJ/moldür. Bir sodyum atomuna 3,38.10 $\mathrm{J}$ enerji verilirse (589 $\mathrm{nm}$ deki bir fotonu absorplarsa), 3s $\rightarrow$ 3p geçişini yapar. Dış kabuk elektronu $3 p$ de olan 1,0 mol atomdan 1,0 mol elektron koparmak için gerekli olan enerji, sodyumun verilen iyonlaşma enerjisinden yaklaşı $2,0 \mathrm{~kJ} / \mathrm{mol}$ kadar eksik olur. Benzer şekilde, $5 s$ veya 5 p deki elektronları koparmak için gerekli enerji daha da küçük olacaktır.

Buna göre, iyonlaşma enerjisinin tanımında şunlar belirtilmelidir:

a) Elektronu koparılacak atomun konumu; elektron vermesini kolaylaştıracak veya zorlaştıracak bir ortamda mıdır?

b) Atomdan hangi elektronun koparılacağı ve bu elektronun konumu; değerlik elektronu değerlik elektron kabuğunda mı, yoksa enerji alarak daha üst katmana çıkmış mıdır?

\section{2 İyonlaşma Enerjisinin Ders Kitaplarında Tanımlanması}

İyonlaşma enerjisi konusunda ders kitaplarında verilen tanımlarda bir kargaşa vardır. Bu kargaşa iki farklı noktada toplanmaktadır: İyonlaşma enerjisini tanımlarken elektronu kopartılacak olan atomun ve bu atomdan kopartılacak olan elektronun konumlarının ifade edilmesinde kullanılan alt kavramlar hem birbirlerinden çok farklı ve hem de öğrenciler tarafından anlaşılması zor ve yanlış kavramalara neden olabilecek şekildedir. Bu ifadelerle ilgili örnekler ve bunların kitaplardaki görülme sıklığı Tablo $1^{\prime}$ de verildi. İyonlaşma enerjisinin tanımında yer alan elektronu koparılacak olan atomun konumu için beş ve bu atomdan hangi elektronun koparılacağı ile ilgili dört etiket belirlendi. 
Tablo 1

Ders Kitaplarındaki Yanlış Ifadeler Ve Görülme Sıklığı (\%)

\begin{tabular}{|c|c|c|c|c|c|c|}
\hline Tema & Etiket & ifade & TL & TÜ & ít & iü \\
\hline \multirow{5}{*}{$\begin{array}{l}\text { Elektronu } \\
\text { koparılacak } \\
\text { atomun } \\
\text { konumu }\end{array}$} & izole gaz & - izole gaz halindeki bir atom & 6 & 0 & 17 & 18 \\
\hline & gaz hali & - gaz halindeki bir atom & 43 & 75 & 17 & 46 \\
\hline & nötral atom & $\begin{array}{l}\text { - gaz halindeki nötral bir atom } \\
\text { - gaz fazında nötr }\end{array}$ & 29 & 25 & 17 & 9 \\
\hline & bir mol atom & $\begin{array}{l}\text { - gaz halindeki bir mol atom } \\
\text { - bir elementin }\end{array}$ & 21 & 0 & 17 & 18 \\
\hline & atom & - bir atomdan & 14 & 0 & 0 & 27 \\
\hline \multirow{4}{*}{$\begin{array}{l}\text { Elektronun } \\
\text { konumu }\end{array}$} & gevşek bağ|ı & - en gevşek bağlı elektron & 6 & 0 & 17 & 18 \\
\hline & yüksek enerjili & $\begin{array}{l}\text { - en yüksek enerjili elektron } \\
\text { • en yüksek enerji düzeyindeki elektron }\end{array}$ & 14 & 25 & 17 & 0 \\
\hline & dış kabuk & $\begin{array}{l}\text { - en dış enerji kabuğundaki elektron } \\
\text { - en dış kabuktaki elektron }\end{array}$ & 29 & 0 & 33 & 18 \\
\hline & minimum enerji & - en az enerji gerektiren elektron & 14 & 0 & 17 & 36 \\
\hline
\end{tabular}

İyonlaşma enerjisi kavramının tanımı yapılırken "elektronu kopartılacak atom" ile ilgili açıklamalarda vurgu yapılması gereken husus "izole bir atom" olmasıdır. Ancak özellikle basım dili Türkçe olan ders kitaplarında yapılan tanımlarda izole ifadesi yerine "gaz halindeki atom" ve "gaz halinde nötral bir atom" ifadesi sıklıkla tespit edildi. Basım dili İngilizce olan ders kitaplarında ise benzer ifadelerin yanında "izole" kavramının "izole gaz halindeki bir atom" şeklinde ifade edildiği belirlendi. Ders kitaplarının hemen hepsinde "izole gaz, gaz hali, nötral atom" gibi benzer ifadeler kullanılmasına rağmen, sadece bir Türkçe kitapta "izole" kavramına rastlanıldı. Bazı ders kitaplarında da tanım yapılmadan bir iyonlaşma tepkimesi verildiği ve "bu tepkimedeki enerji değişimidir" şeklinde açıklandığı veya aynı kitapta birden fazla farklı tanımlamaların yapıldığı görüldü.

İyonlaşma olayı sırasında "kopan elektronun konumu" hakkında bilgi verilirken atomun uyarılmadığına (yani değerlik elektronunun kendi orbitalinde bulunması) vurgu yapmak için "temel hal" üzerinden açıklama yapılmalıdır. Ancak kitaplarda verilen tanımlarda genellikle temel hal belirtilmiş olsa da; "gaz fazında temel haldeki bir atom" ifadesi içinde kullanıldığı belirlendi. Elektronun konumu, basım dili Türkçe olan ders kitaplarında genellikle "en yüksek enerjili elektron", "en yüksek enerji seviyesindeki elektron" veya "en dış kabuktaki elektron" ifadeleri ile tanımlanmaktadır. Basım dili İngilizce olan ders kitaplarında ise elektronun veya bulunduğu kabuğun enerjisinden yararlanılarak tanımlamanın çok tercih edilmediği belirlendi. Bu kitaplarda ise elektron için "en az enerji gerektiren elektron" ifadesi daha sık tespit edildi.

Sonuç olarak, basım dili ve hitap ettiği öğrenci seviyesine göre kitaplardaki iyonlaşma enerjisi tanımları birbirlerinden çok farklı değildir. Illaveten tanımlar daha önce belirtilen kriterleri içermemekte yani kavramsal olarak doğru değil ve öğrencileri alternatif kavramalara yönlendirecek şekildedir.

\section{SONUÇ, TARTIŞMA VE ÖNERILER}

$\mathrm{Bu}$ araştırmanın amaçları doğrultusunda kimya ders kitaplarında verilen tanımlar irdelendiğinde, iyonlaşma kavramının tanımının (i) elektronu koparılacak atomun konumu ve (ii) iyonlaşacak elektronun konumu açısından çok dolaylı olduğu, hatta bazılarının anlaşıı olmadığı söylenebilir. Ders kitaplarının yazarlarının tanımlarında yer alan "izole gaz halindeki bir atom", veya "gaz halindeki bir atom" ifadeleri ile ne söylemek istedikleri belki fen alanında 
veya fen eğitimindeki uzmanlar tarafından anlaşılabilir, ancak öğrenciler için uygun olmayan ve hatta alternatif kavramalara neden olabilecek ifadelerdir. Ben-Zvi, Eylon ve Silberstein'in (1986) lise öğrencileriyle yaptığı çalışmada "atomların maddenin bir parçası olduğu ve bir atom, gaz veya katı halden izole edilirse o halin özeliklerini taşıyacağını" düşündüklerini belirlemiştir. Bu yüzden ders kitaplarında "bir gaz atom", "izole gaz halindeki bir atom" gibi ifadelerin öğrencileri alternatif kavramalara sevk edebileceği düşünülmektedir.

"Gaz fazında temel halde bir atom" ifadesindeki "temel hal" uygun ve anlaşlır olmasına rağmen; gaz halindeki bir maddenin bir atomu izole değildir ve bir atomun "hal" durumundan söz edilemez. Çünkü gaz maddenin bir halidir ve atomların bulunduğu bir ortamda bir atom, diğer atomların itme-çekme kuvvetleri etkisinde olacağından izole olması mümkün değildir. Aslında yazarlar "gaz" ifadesi ile "ideal gaz" kavramını çağrıştırmak istiyor olabilirler. İdeal gazlarda gazı oluşturan taneciklerin birbirlerini etkilemedikleri, itmedikleri veya çekmedikleri varsayımı dikkate alınırsa, ideal gazı oluşturan atomların da izole olduğu kabul edilebilir. Ancak bu anlama ulaşma sürecinin ders kitabında öğrenciye bırakılmaması gerekir.

Genç (2008), lise öğrencilerinin iyonlaşma enerjisini tanımlarken "izole" ifadesini kullanmadıklarını belirlemiştir. Ayrıca aynı öğrenci grubu, bir atomu iyon haline getirmek için en uygun halin katı hal olduğunu, çünkü sıvı ve gazlarda atomlar dağınık halde olduğundan iyonlaşmanın zor olacağını düşünmektedir. Bu düşünce bilimsel modele aykırıdır. Bu sebeple kimya öğretiminde iyonlaşma enerjisi tanımlanırken özellikle atomların "izole" durumda olduklarına vurgu yapılmalıdır. "izole" ifadesinden sonra ise bir halden bahsetmek kavramsal olarak uygun değildir.

Tanımlardaki "bir elementin iyonlaşma enerjisi" ifadesi de iyonlaşma enerjisinin kavramsal tanımını yansıtmamaktadır. Deneysel ve kuramsal yaklaşımlarla atomların iyonlaşma enerjileri belirlendikten sonra, element için mol başına iyonlaşma enerjisi hesaplanarak verilmektedir. İyonlaşma, maddenin bütünsel yapısı ile ilgili bir özellik değildir.

Atomun iyonlaşması sırasında koparılacak olan elektron ders kitaplarında “...en yüksek enerjili.. en gevşek bağlı... en az enerji gerektiren.." gibi ifadelerle belirtilmekte, "bir atomda çekirdekten uzaklaştıkça elektronların enerjilerinin artacağı, yüksek enerjili elektronların daha gevşek bağlı olduğu ve bu elektronları atomdan uzaklaştırmak için daha düşük enerji gerektiği" gibi öğrencinin bir kavramsal çatı oluşturmuş olması beklenmektedir. Ancak bu açıklamalar öğrenciler için anlaşılır olmayabilir. Üstelik uyarılmış atomun en dış katmanındaki elektronu, temel haldekine göre daha da yüksek enerjilidir ve koparmak için daha az enerji gerektirir. Bu sebeple "en gevşek bağlı", "yüksek enerjili" veya "en dış enerji kabuğundaki" gibi ifadelerden öğrencinin elektronun konumu için "uyarılmış haldeki elektron" dan değil "temel haldeki elektrondan" bahsedilmeye çalışıldığını anlaması beklenilmektedir.

Sonuç olarak; iyonlaşma enerjisi tanımlarında mutlaka atomun "izole ve temel halde" olduğu belirtilmelidir. Bu durumu açıklamak biraz karmaşık olduğundan, yine sodyum ve klor atomları üzerinden söylemek istediğimizi açıklayalım. Temel haldeki bir sodyum atomunun değerlik elektronu 3s orbitalindedir. Bir sodyum atomunun 3s deki elektronunu çekirdeğin çekim alanından çıkarmak, yani atomdan koparmak için verilmesi gereken enerji "iyonlaşma enerjisi" (bu değerin Avogadro sayısıyla çarpımı I. molar iyonlaşma enerjisi) dir. Uyarılmış bir sodyum atomundan, örneğin değerlik elektronu $3 s \rightarrow 3 p$ geçişi yapmış olan, bir elektronu koparma olayı da iyonlaşmadır. Ancak, $3 p^{\prime}$ deki bir elektronu koparmak için sisteme verilmesi gereken enerjinin Avogadro sayısıyla çarpımından elde edilecek değer, sodyumun I. molar iyonlaşma enerjisi değildir.

Sodyum ve klor atomlarının her ikisinin de iyon haline geçmesinin iyonlaşma olduğu dikkate alınarak, iyonlaşma enerjisinin tanımı aşağıdaki şekilde yapılabilir: 


\section{"I.molar iyonlaşma enerjisi, temel halde izole 1,0 mol atomdan 1,0 mol elektronu koparmak veya 1,0 mol atoma 1,0 mol elektron vermek için gerekli enerji değişimidir."}

Kimyanın kavramlarıyla ilgili formal tanımlar International Union of Pure and Applied Chemistry (IUPAC) tarafından yapılmaktadır. Ders kitaplarının yazarlarından da beklenen, yazdıkları kitaplardaki temel kavramları IUPAC tanımlarına uygun olarak vermeleridir. IUPAC'ın iyonlaşma enerjisi tanımı "temel haldeki nötral bir atom veya molekülden bir elektron koparılması için gerekli en düşük enerji" şeklindedir (IUPAC, 1997).

IUPAC'ın tanımlarının bilimsel açıdan doğruluğunu tartışmamız bizim için mümkün değildir. Ancak, bu tanımları kimya eğitimi açısından irdeleyebileceğimizi düşünüyoruz. İyonlaşma enerjisi tanımındaki "temel hal" ve "en düşük enerji" birlikte verildiği için anlamlıdır, ancak ders kitaplarına yansıması sadece "en düşük enerji" şeklinde olmuştur. Atom temel halde olduğu takdirde, değerlik elektronu en dış kabuk orbitalindedir. Temel halde olmaması durumunda, değerlik elektronu en üst katmana uyarılabilir ve uyarılmış bir atomdan elektronu koparmak için temel hale göre daha düşük enerji gerekir. Tanımdaki "nötral" ifadesi fazladır ve öğrencide "nötral olmayan atom" kavraması oluşturabilir. Atom, zaten nötrdür.

Kavramlar, kitaplar ve benzeri kaynaklarda mutlaka kavramsal içeriğine uygun olarak tanımlanmalıdır. Ancak, eğitim öğretim amacıyla kullanılacak olan kaynaklarda yapılan kavram tanımlarında, öğrencilerin kavramsal gelişimine destek olunacak ve kavramı kavramalarını sağlayacak ifadelere özen gösterilmelidir.

Kitapların incelenmesi ile elde edilen bulgular ve literatürdeki çalışmalar ışı̆̆ında, iyonlaşma enerjisi bilimsel modele uygun olarak "temel halde izole bir atomdan bir elektron koparılması için verilmesi gereken enerji" olarak tanımlanabilir. Benzer şekilde, I.molar iyonlaşma enerjisi de "temel halde izole 1,0 mol atomdan 1,0 mol elektron koparılması için verilmesi gereken enerji" şeklinde tanımlanabilir.

Kimyadaki kavramların öğrencileri de dikkate alınarak tanımlanması o kavramın bilimsel görüşe uygun olarak kavranması açısından önemlidir. Bu araştırmada temel kimya kavramlarından sadece iyonlaşma enerjisi kavramsal olarak irdelendi. Ders kitaplarının incelenmesi aşamasında iyonlaşma enerjisi ile bağlantılı elektron ilgisi kavramının tanımında da kavramın öğrenciler tarafından anlaşılmasını etkileyecek ve onları alternatif kavramalara sevk edebilecek ifadeler gözlemlendi. Bu sebeple elektron ilgisi kavramının da bu araştırmadaki yaklaşım dikkate alınarak irdelenmesinin öğrenciler ve eğitimciler için faydalı olacağı düşünülmektedir.

\section{KAYNAKLAR}

Barke, H. D., Hazari, A. ve Yitbarek, S. (2009). Misconceptions in chemistry: Addressing perceptions in chemistry education. Berlin: Springer.

Barker, V. (2000). Beyond appearances: Students' misconceptions about basic chemical ideas. A report prepared for the Royal Society of Chemistry. London: Royal Society of Chemistry. [http://www.chemsoc.org/networks/learnnet/miscon.htm]).

Ben-Zvi, R., Eylon, B. S., ve Silberstein, J. (1986). Is an atom of copper malleable? Journal of Chemical Education. 63(1), 64.

Bogdan, R., ve Biklen, S. K. (1997). Qualitative research for education. Boston: Allyn and Bacon.

Bretz, S.L. ve McClary, L. (2015), Students' understandings of acid strength: How meaningful is reliability when measuring alternative conceptions? Journal of Chemical Education. 92(2), 212-219. 
Coll, R. K., ve Treagust, D. F. (2003). Investigation of secondary school, undergraduate, and graduate learners' mental models of ionic bonding. Journal of Research in Science Teaching, 40(5), 464-486.

Gabel, D.L. ve Samuel, K.V. (1987). Understanding the particulate nature of matter. Journal of Chemical Education. 64(8), 695-697.

Genç, Ş. (2008). Sosya-kültürel oluşturmacllık temelinde tasarlanan öğretimin ortaöğretim öğrencilerinin periyodik özellikleri öğrenmeleri üzerine etkisinin belirlenmesi. (yayınlanmamış Yüksek Lisans Tezi). Marmara Üniversitesi, İstanbul.

Griffiths, A. K., Thomey, K., Cooke, B., ve Normore, G. (1988). Remediation of student-specific misconceptions relating to three science concepts. Journal of Research in Science Teaching 25: 709-719.

Harrison, A. G., ve Treagust, D. F. (1996). Secondary students' mental models of atoms and molecules: Implications for teaching chemistry. Science education,80(5), 509-534.

IUPAC. Compendium of Chemical Terminology, 2nd ed. (the "Gold Book"). Compiled by A. D. McNaughtand A. Wilkinson. Blackwell Scientific Publications, Oxford (1997). XML on-line corrected version: http://goldbook.iupac.org (2006-) created by M. Nic, J. Jirat, B. Kosata; updates compiled by A. Jenkins. ISBN 0-9678550-9-8. doi:10.1351/goldbook

Karasar, N. (2008). Bilimsel araştırma yöntemi: Kavramlar, ilkeler, teknikler. Ankara: Nobel yayın dağıtım Tic. Ltd. Şti.

Kılıç, Z., Atasoy, B., Tertemiz, N., Şeren, M., ve Ercan, L. (2001). Fen bilgisi 4-8, konu alanı ders kitabı inceleme kılavuzu. Ankara: Nobel Yayın Dağıtım

Köseoğlu, F., Atasoy, B., Kavak, N., Akkuş, H., Budak, E., Tümay, H., ... ve Taşdelen, U. (2003). Yapılandırmacı öğrenme ortamı için bir fen ders kitabı nasıl olmalı. Ankara: Asil YayınDağıtım.

Nakhleh, M., (1992). Why some students don't learn chemistry: Chemical misconceptions, Journal of Chemical Education, 69(3), 191-196).

Nakiboglu, C. (2003). Instructional misconceptions of Turkish prospective chemistry teachers about atomic orbitals and hybridization. Chemistry Education Research and Practice,4(2), 171-188

National Research Council [NRC].(1996).National science education standards. National Academies Press.

Nussbaum, J. (1981). Towards a diagnosis by science teachers of pupils' misconceptions: An exercise with student teachers. International Journal of Science Education 3: 159-169.

Pauling, L. (1970). General Chemistry. 3. Edition. San Francisco: W.H. Freeman and Company.

Sanger, M. J., ve Greenbowe, T. J. (1997). Students' misconceptions in electrochemistry: Current flow in electrolyte solutions and the salt bridge. Journal of Chemical Education, 74(7), 819.

Sanger, M. J., ve Greenbowe, T. J. (1999). An analysis of college chemistry textbooks as sources of misconceptions and errors in electrochemistry. Journal of Chemical Education, 76(6), 853.

Schmidt, H.-J. (1997). Students' misconceptions - looking for a pattern. Science Education. 81: 123-135. 
Skoog, D. A., Holler, F. J., ve Crouch, S. R. (2007).Principles of instrumental analysis. Thomson Brooks/Cole.

Staver, J. R., ve Lumpe, A. T. (1993). A content analysis of the presentation of the mole concept in chemistry textbooks. Journal of Research in Science Teaching, 30(4), 321-337.

Taber, K. S. (1998). The sharing-out of nuclear attraction: Or I can't think about physics in chemistry. International Journal of Science Education. 20, 1001-1014.

Taber, K. S., (2002). Alternative conceptions in chemistry: Prevention, diagnosis and cure. London: The Royal Society of Chemistry.

Taber, K. S., ve Tan, K. C. D. (2011). The insidious nature of 'hard-core'alternative conceptions: Implications for the constructivist research program of patterns in high school students' and pre-service teachers' thinking about ionization energy. International Journal of Science Education,33(2), 259-297.

Taber, K.S. (2003). Understanding ionization energy: Physical, chemical and alternative conceptions, Chemistry Education: Research and Practice. 4(2), 149-169).

Talim Terbiye Kurulu [TTK] (2005). Ilköğretim Fen ve Teknoloji Dersi (4. ve 5. Sınıflar) Öğretim Programı. https://ttkb.meb.gov.tr/www/ogretim-programlari/icerik/72.

Tan, K. C. D., Taber, K. S., Goh, N. K., ve Chia, L. S. (2005). The ionization energy diagnostic instrument: a two - tier multiple-choice instrument to determine high school students' understanding of ionization energy. Chemistry Education Research and Practice.6(4), 180-197.

Tan, K. C. D., ve Taber, K. S. (2009). Ionization energy: Implications of pre-service teachers' conceptions. Journal of Chemical Education, 86(5), 623.

Tan, K. C. D.,Taber, K. S., Liu, X., Coll, R. K., Lorenzo, M., Li, J., ve Chia, L. S. (2008). Students' conceptions of ionization energy: A cross cultural study. International Journal of Science Education.30(2), 263-283.

Tekin, B. B., ve Nakiboglu, C. (2006). Identifying students' misconceptions about nuclear chemistry. A study of Turkish high school students. Journal of Chemical Education, 83(11), 1712

Tezcan, H. ve Kıpık, M. (2005). Lise 1. sınıf öğrencilerine periyodik tablo öğretiminde yeni bir yaklaşım. Milli Eğitim Dergisi, 33(166), 257-276.

Treagust, D. F. (1988). Development and use of diagnostic tests to evaluate students' misconceptions in science. International Journal of ScienceEducation. 10: 159-169.

Tsaparlis, G. ve H. Sevian (2013). Introduction: Concepts of matter- complex to teach and difficult to learn. G. Tsaparlisand H. Sevian (eds.), Concepts of matter in science education, innovations in science education and technology 19, DOI 10.1007/978-94007-5914-5_1

Yalçın, A., ve Kılıç, Z. (2005). Öğrencilerin Yanlış Kavramaları Ve Ders Kitaplarının Yanlış Kavramalara Etkisi Örnek Konu: Radyoaktivite. GÜ, Gazi Eğitim Fakültesi Dergisi, 25(3), $125-141$.

Yıldırım, A., ve Şimşek, H. (2008). Sosyal bilimlerde nitel araştırma yöntemleri. Ankara: Seçkin Yayıncilık. 


\section{Ek. İncelenen Ders Kitapları}

1) Ortaöğretim Kimya 9. Sınıf . (2013). Komisyon. Milli Eğitim Bakanlı̆̆ Yayınları. Devlet Kitapları.

2) 9. Sinıf Kimya Konu Anlatımı (2013). Hamza Ceylan, Yasin Kayar, Eylem Bulut. Esen Yayınları

3) Ortaöğretim Kimya 9 Ders Kitabı (2013) . Yüksel Altun, Halil Tümay. Sözcü Yayıncılık Pazarlama

4) Ortaöğretim Kimya Ders Kitabı 10. Sınıf (2013). Mehmet Faruk Dursun, ibrahim Gülbay, Serpil Çetin, Ümit Tek, Filiz Fatma Özkoç, Mehtap Güntut. Saray Matbaacılık. Ankara.

5) Ortaöğretim Kimya 11 Ders Kitabı. (2014). Nusret Kavak. Mega yayınclık. Ankara

6) Ortaöğretim Kimya 9. Sınıf (2015). Komisyon. Milli Eğitim Bakanlığı Yayınları. Devlet Kitapları.

7) Ortaöğretim Kimya 9. Sınıf (2015). Ali Kemal Bilenler. Ada Matbaacılık Yayıncılık San. ve Tic. Ltd. Ş. Ostim

8) 11. Sınıf Ortaöğretim Kimya Ders Kitabı (2015). Hilmi Badur. Evrensel Illetişim Yayınları. Altındağ Ankara

9) 11. Sınıf Kimya Konu Anlatımı (2015). Hamza Ceylan, Yasin Kayar, Eylem Bulut. Esen Yayınları

10) Ortaöğretim Kimya 9 Ders Kitabı (2016). Filiz Sarıten Aydoğan. Dikey Yayıncılık. Keçiören Ankara

11) Ortaöğretim Kimya 9 Ders Kitabı. (2016). Sevgi Kıngır. Tuna Matbaacılık San. ve Tic. A.Ş. Şaşmaz.

12) Ortaöğretim Kimya 9. Sınıf (2016). Komisyon. Milli Eğitim Bakanlığı Yayınları. Devlet Kitapları.

13) Ortaöğretim Kimya 9 Ders Kitabı. (2016). Faruk Karaca. Paşa yayınları. Ankara.

14) Ortaöğretim Kimya 11 Ders Kitabı. (2016) Nusret Kavak.

15) Petrucci, R., Herring, F.G., Madura, J.D. ve Bissonnete, C. (2012). Genel Kimya-ilkeler ve Modern Uygulamalar. (Çev. Tahsin Uyar, Serpil Aksoy, Recai İnam). Ankara:Palme

16) Atkins, P., Jones, L. (1998) Temel Kimya- Moleküller, maddeler ve Değişimler (Çev. Esma Kılıç, Fitnat Köseoğlu, Hamza Yılmaz). Ankara: Bilim Yayıncılık

17) Chang, R. (2009). Genel Kimya - Temel Kavramlar (Çev. Tahsin Uyar, Serpil Aksoy, Recai Inam). Ankara: Palme Yayıncilık.

18) Mortimer, C.E (2004). Modern Üniversite Kimyası. (Çev. T. Altınata, H. Akçay, H. Anıl, H. Avcıbaşı, D. Balıköse, S. Çelebi, E. Henden, G. Nişli, M. Toprak, D. Tosalı, B. Yenigül).Beyoğlu: Çağlayan Kitabevi.

19) Mc Murry, J., Fay, R.C. (2004). Chemistry. Pearson Educational International.

20) Brown, T., LeMay, H.E., Bursten, B.E., ve Murphy, C. (2009). Chemistry -The Central Science. Pearson Education, Inc. Upper Saddle River.

21) Wilson, C.A. (2013). Passing the State Science Proficiency Tests: Essential Content for Elemantary and Middle School Teachers

22) Whitten, K.W., Davis, R. E., Peck, M.L., Stanley, G.G. (2014). Chemistry. Tenth Edition. Cengage Learning. USA

23) Jain (1998). Competition Science Vision. Upkar Prakashan. Agra.

24) Malone, L.J.ve Dolter, T. (2010). Basic Concepts of Chemistry. John Wiley ve Sons, Inc. Danver. USA

25) Reger, D.L., Goode, S.R., ve Ball, D.W (2010). Chemistry: Principles and Practice. Tenth Edition. Cengage Learning. USA

26) Atkins, p. ve De Paula, J. ( 2013 ). Elements of Physical Chemistyr. 6th Edition. Oxford University press. Oxford.

27) Ebbing, D. ve Gammon, S.D. (2013). General Chemistry, Enhanced Edition Cengage Learning. USA

28) Chandra, S. (2006). Comprehensive Inorganic Chemistry. New Age International Publishers. New Delphi

29) Chang, R. (2014) e-Study Guide for: Chemistry: An Introductionto General Chemistry. Cram101 Textbook Reviews.

30) Holleman, A.F. ve Wiberg, E. (2001). Inorganic Chemistry. Academic Press. London, UK.

31) Ryan, L., ve Norris, R. Cambridge International AS and A Level Chemistry Coursebook (Second Edition). Cambridge Universitry Press. Cambridge

32) Chang, R. ve Cruickshang (2005). Chemistry. McGraw-Hill. New York.

33) Clugston, M. ve Flemming, R. (2000). Advanced Chemistry. Oxford University Press. Uk

34) Myers, R. (2003). The Basic of Chemistry . Green Wood Press. London.

35) Boeyens, J. C. A. (2003). The Theories of Chemistry. Elsevier B.V. Amsterdam. Hollanda 


\section{SUMMARY}

\section{A Conceptual Approach to the Definition of Ionization Energy}

The concept of ionization energy has a key role in the comprehension of atomic structure, changes in the periodic table and chemical reactions (Taber, 2003); however, this topic is difficult for students to understand (Taber, 1998; Taber, 2003). It has been found that students develop two important alternatives to this concept. The first is the case whereby an atom has a full atomic shell, which is steady and desired by the atom (Tan et al., 2005; Tan et al., 2008; Tan ve Taber, 2009). The other asserts that after the atom is ionized, the energy to distance the second electron is higher because this electron is closer to the nucleus (Taber, 1998; Taber, 2002; Taber, 2003). There is a dearth of research on ionization energy in Turkey (Genç, 2008; Tezcan ve Kıpık, 2005), and these alternative conceptions are compatible with those determined by Taber $(1998,2002)$. Previous experiences influence students' alternative conceptualizations (Harrison ve Treagust, 1996). Textbooks may also prevent students from comprehending concepts in a scientific way (Harrison ve Treagust, 1996; Sanger ve Greenbowe, 1999; Staver ve Lumpe, 1993; Yalçın ve Kılıç, 2005). There are many studies of students' alternative conceptions about almost every field and the effect of textbooks on them.

This study aims to define ionization energy and evaluate its definitions in textbooks. The subconcepts in the textbook definitions and their appropriateness to scientific thinking were examined.

The study used interviews, observation and document analysis and qualitative research design (Bogdan ve Biklen, 1992; Yıldırım ve Şimşek, 2008). Thirty-five Turkish and English chemistry textbooks were analyzed using content analysis. Twenty-one of the textbooks were in English, and 14 were in Turkish.

An analysis of the textbooks' definitions of ionization energy found chaos. When defining ionization energy, the subtopics used for defining the location of the electron to be ejected and the atom whose electron will be ejected varied highly and were difficult to understand by students, which may lead to misconceptions. In the definition of the ionization energy concept, the point to be emphasized in the explanation of "the atom whose electron will be ejected" is the fact that it is an "isolated atom". However, in the definition of Turkish books, instead of the term, "isolated", the expressions, gaseous atom and neutral gaseous atom, were frequently used. In addition to similar expressions, in the English textbooks the isolated concept was described as isolated gaseous atoms. Although almost all of them used expressions such as isolated gas, gaseous, neutral atom, only one Turkish book used the term, isolated. In some books, the ionization reaction was given without a definition and was explained as, "this is the energy change in the reaction," or there were more than one explanation in the same book. When giving information about the location of the ejected electron during ionization, in order to stress the fact that the atom is not stimulate (i.e., the valence atom was in its own orbital), the explanation should be made using the idea of aground state. However, in the textbook definitions, although the ground state is shown, the expression, a gaseous atom in its ground state, was used. In the Turkish textbooks, the location of the electron was defined as the electron with the highest energy, the electron with the highest energy level or the electron in the outermost shell. The English textbooks, however, did not use definitions based on the electron's or its shell's energy. In these textbooks, the electron that requires the least energy was used more frequently.

The findings from the textbook analyses and the literature indicate that ionization energy can be scientifically defined as the energy required to eject an electron from an isolated atom in its ground state. Similarly, primary molar ionization energy can be defined as the energy required to eject 1.0 mole of electrons from a 1.0 mole of isolated atoms in its ground state.

Student-friendly definitions of chemical concepts are important in terms of scientific comprehension. Of chemistry concepts, only ionization energy was examined in this study. Analysis of the textbooks found that some expressions used in the definition of the electron in relation to ionization energy could lead to misunderstandings and alternative conceptualizations. For this reason, the concept of the electron should be examined on the basis of the scientific view adopted by this study. 